\title{
An optical sensor for selenite determination in aqueous samples
}

\author{
Preeti Sunil Kulkarni ${ }^{1 *}$, Priyanka V. Ramekar ${ }^{2}$ and Sunil D. Kulkarni ${ }^{3}$
}

\begin{abstract}
Background: In the present work, an optical sensor has been developed for the determination of selenium (IV) in aqueous samples. The optical sensor is a cellulose triacetate plasticized membrane with tri-octyl methyl ammonium chloride (Al-336) immobilized in it as an ion exchanger.

Methods: The sensor works in two steps. In the first step, a $1 \times 2 \mathrm{~cm}$ piece of the membrane is allowed to equilibrate with a known amount of selenium (IV) solution and potassium iodide in acidic medium. During this equilibration, the iodometric reaction takes place and, $\Gamma_{3}$ (tri-iodide anion) is formed which gets sorbed into the membrane due to which the colorless film changes to yellow color showing an absorption maxima at $355 \mathrm{~nm}$ which is a characteristic of $\Gamma_{3}$. In the second step the $\Gamma_{3}$ loaded membrane is allowed to equilibrate with a solution of variamine blue dye in presence of sodium acetate. In this step, oxidation of the dye takes place and the membrane shows a color change from yellow to violet and a shift in the absorption maxima from 355 to $550 \mathrm{~nm}$.

Results: The method is used to study the quantitative determination of selenium in aqueous samples, where the amount of selenium is varied and the corresponding absorbance at $550 \mathrm{~nm}$ is measured. A good linear curve is obtained in the concentration range of 0.2 to $3 \mu \mathrm{g} \mathrm{mL}^{-1}$ of selenium.

Conclusions: The proposed method can be successfully applied to determination of selenium (IV) in various pharmaceutical and environmental samples.
\end{abstract}

Keywords: Selenium, lodometry, Variamine blue, Tri-iodide, Sensor

\section{Background}

Selenium is an important trace element required for proper metabolism in animals and human beings. Deficiencies as well as over intake both are problem causing in living organisms (Ventura et al., 2009). The two main inorganic forms of selenium in aqueous systems are selenite (IV) and selenate (VI). Out of the two forms selenite, Se (IV) is more toxic than selenate to living organisms. Also, the bioaccumulation of Se (IV) is more than Se (VI). The maximum permissible limit of Se (IV) in drinking water, as recommended by WHO, is $10 \mathrm{ppb}$ (Bleiman \& Mishael, 2010). Hence, the determination of Se (IV) in aqueous systems is of more scientific interest. There are many analytical techniques available for the determination of Se (IV) in aqueous systems (Pettine \& McDonald, n.d.). The most common one used is

\footnotetext{
* Correspondence: preeti.kulkarni@mesagc.org

${ }^{1}$ MES Abasaheb Garware College, Post Graduate and Research Centre,

Department of Chemistry, Pune, India

Full list of author information is available at the end of the article
}

spectrophotometry using selective reagents. Se (IV) monitoring has been studied by Md Rabiul et al. using a composite adsorbent with immobilization of organic ligands which give a color change with selenite (Rabiul Awul et al., 2015). A flow injection technique has been described in literature where the oxidation reaction of 3 methyl-2benzothiazolinone hydrazone hydrochloride by selenite followed by coupling reaction with chromotropic acid has been used (Rekha et al., 2006). Apart from spectrophotometric methods, other methods of Se (IV) determination commonly employed include nuclear techniques (Alamin et al., 2006; Yusof, 1997), atomic absorption spectroscopy (Capelo et al., 2006; Hegedus et al., 2008) and inductively coupled mass spectrometry (Chen et al., 2007; Ohki et al., 2016; Jagtap \& Maher, 2016), and voltammetry (Devi et al., 2017) etc.

However, most of these methods require sophisticated equipment and are both complex and less economical. Thus, development of a simple, rapid, and economical 
method for determination of Se (IV) in aqueous solution is scientifically important.

Iodometric method is one of the convenient and simple methods for determination of Se (IV) in solution. The reaction involves the oxidation of $I^{-}$ions into $I_{2}$ by $\mathrm{SeO}_{3}^{2-}$ and its subsequent reaction with excess $I^{-}$to form $I_{3}$. In conventional iodometry, this liberated iodine is titrated with sodium thiosulphate using starch as an indicator (Vogel, 1989). Iodometric reaction provides many fold amplification of the signal (Zhang et al., 1998); however, there are chances of loss of liberated iodine during titration. These losses of iodine can be prevented if the liberated iodine is treated with an iodine selective reagent such as a dye giving a good optical response. In literature, certain iodine selective reagents have been used like pamino- $\mathrm{p}^{1}$-methoxydiphenylamine, cetylpyridinium cation etc. (Revansiddappa \& Kiran Kumar, 2001; Agrawal et al., 2009). Another possibility of measurement of liberated iodine is its preconcentration into a solid phase matrix that can further enhance the analytical capability of the method and can also prevent the loss of iodine during sample handling and manipulation. One such solidphase matrix used in the literature is nafion membrane with suffused p-amino-p'-methoxydiphenylamine or variamine blue (variamine blue) dye in it (Coo et al., 1999). The method involved reacting selenite with potassium iodide to generate iodine gas, which reacts with variamine blue to form a violet colored species monitored spectrophotometrically. Nafion membranes are commercially available membranes. The method is efficient in selenium (IV) analysis; however, it is not very economical.

With this background in the present work, we have employed the same iodometric reaction for generation of iodine with a cellulose triacetate membrane plasticized with di-octyl phthalate containing Al-336 anion exchanger as the solid phase medium. The solid phase medium is employed as an optical sensor for Se (IV) determination using iodometric reaction The chemical conditions required for the iodometric reaction between $\mathrm{SeO}_{3}^{2-}$ and $I^{-}$in presence of acid were optimized in our earlier work using ${ }^{131} I$ radiotracer and it indicated that the iodine sorption in the membrane is quantitative, reproducible, and without any losses (Bhagat et al., 2008). Cellulose tri-acetate is a highly crystalline, hydrophobic base polymer, that enhances mechanical strength and provides stability to the membrane. Cellulose triacetate is highly beneficial as a polymer material for metal ion removal as it creates minimum hindrance to the transport of ions within the membrane (Flory, 1953). Di-octyl phosphate is a plasticizer used which increases softness and enhances flexibility in the membrane. DOP penetrates into the membrane and neutralizes the polar groups in the membrane with its own groups (Sears \& Darby, 1982). Iodine enters into the membrane as tri-iodide ion as it forms an ion pair with tri-octyl methyl ammonium chloride which is commonly called as Al-336. It is an anion exchanger selective to $I_{3}^{-}$ anion. $\mathrm{Al}-336$ acts as a carrier and facilitates $I_{3}^{-}$ transport across the membrane.

The objective behind the present work was to apply the developed method to study the quantitative determination of selenium (IV) in spiked aqueous samples. The method was used to determine selenite in aqueous samples in presence of interfering ions like oxalate, phosphate, nitrate, bicarbonate, bromate, and chloride.

\section{Methods}

\section{Reagents and equipment}

All reagents used were of analytical reagent grade. Double distilled water from Equitron's instrument was used throughout the work. Variamine blue (p-amino-p'methoxydiphenylamine) was purchased from Merck. Al-336 (Tri-octylmethyl ammonium chloride) was purchased from Sigma Aldrich. Sodium selenite, hydrochloric acid, potassium iodide, Di-octyl phthalate, sodium acetate, dichloromethane, potassium bromate, sodium chloride, ammonium oxalate, potassium chloride, methyl alcohol, chloroform, sodium bicarbonate, ammonium nitrate, potassium nitrate, zinc sulfate, and magnesium carbonate were purchased from Qualigen. All the optical density measurements were done on a UV-visible spectrophotometer (Systronics).

\section{Fabrication of the optical sensor}

The optical sensor was prepared by using the polymer inclusion method described in our earlier work (Bhagat et al., 2007). A solution of cellulose triacetate was prepared by dissolving $0.4 \mathrm{~g}$ cellulose triacetate in $10 \mathrm{~mL}$ dichloromethane. Another solution containing $0.1 \mathrm{~g}$ Aliquat 336 and $0.6 \mathrm{~g}$ Di-octyl phthalate in $10 \mathrm{~mL}$ dichloromethane was prepared. Both the solutions were ultrasonicated for $10 \mathrm{~min}$ to ensure complete homogenization. After homogenization, both the solutions were mixed together to form the casting solution and further ultrasonicated for $5 \mathrm{~min}$ to ensure complete mixing. The amount of cellulose triacetate, Di-octyl pthalate, and Al-336 were optimized by varying their amount in the casting solution to get a membrane with minimum thickness but sufficient mechanical strength required for handling. The homogenous casting solution was then spread on a petri plate with an inner diameter of $9 \mathrm{~cm}$. After complete evaporation of dichloromethane transparent films were peeled off from the petri plate. The membranes were thoroughly washed with water to remove any soluble component, air dried and stored in air tight containers till further use. 


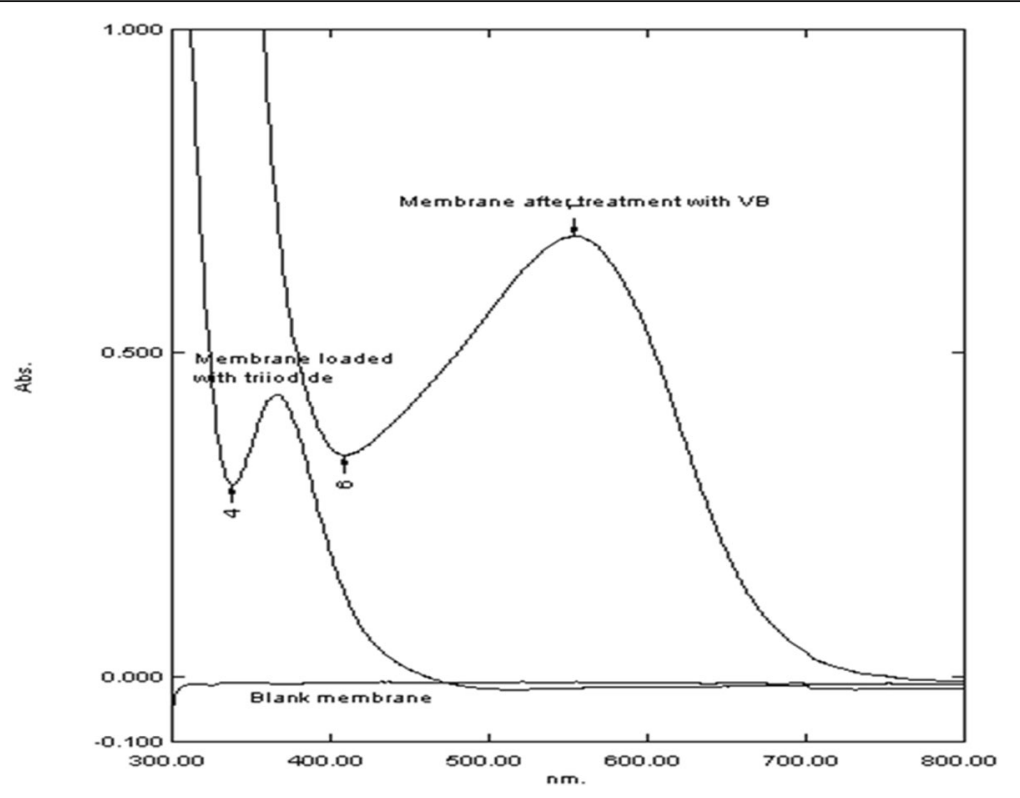

Fig. 1 UV-Visible spectrum of the films a Blank film. b. $\Gamma_{3}$ sorbed film. c variamine blue dye-treated film

\section{Measurement of Se (IV) in solution using variamine blue} dye

The method used for determination of Se (IV) in aqueous samples is briefly described. Se (IV) $(0-20 \mu \mathrm{g})$ was taken in 10-mL volumetric flasks. To each solution, $1 \mathrm{~mL} 2 \% \mathrm{KI}$ and $1 \mathrm{~mL} 2 \mathrm{M} \mathrm{HCl}$ was added. To this solution, $3 \mathrm{~mL}$ variamine blue dye solution $\left(8 \times 10^{-5} \mathrm{M}\right.$ in $1: 2$ solution of methanol to water) and $2 \mathrm{~mL} 1 \mathrm{M}$ sodium acetate was added. The absorbance values of all the solutions were recorded at $550 \mathrm{~nm}$ and a plot of the absorbance values as a function of concentration of Se (IV) in the solution was obtained.

\section{Sorption of $I_{2}$ in sensor}

In the present method, the polymer inclusion films used as the optical sensor fabricated according to the procedure described above was used for determination of selenite in aqueous samples. Required volume of aqueous solution of selenite in the concentration range $2-20 \mu \mathrm{g}$
Se (IV) was taken in 10-mL volumetric flasks containing a $1 \mathrm{~cm} \times 2 \mathrm{~cm}$ piece of optical sensor. To this solution, $1 \mathrm{~mL} 2 \% \mathrm{KI}$ and $1 \mathrm{~mL} 2 \mathrm{M} \mathrm{HCl}$ were added and final dilution was done using distilled water. The solution was allowed to equilibrate with the film for $20 \mathrm{~min}$. The films were washed thoroughly with distilled water and excess water was removed with a filter paper. The absorbance of the film was recorded at $355 \mathrm{~nm}$. The films were then placed into a solution containing $3 \mathrm{~mL}$ of variamine blue and $2 \mathrm{~mL} 1 \mathrm{M}$ sodium acetate. The film was allowed to equilibrate with the solution for $20 \mathrm{~min}$ and the absorbance value of the complex formed in the film was recorded at $550 \mathrm{~nm}$. A calibration curve was obtained at 355 and $550 \mathrm{~nm}$.

\section{Interference studies}

The effect of interfering anions like $\mathrm{Cl}^{-}, \mathrm{SO}_{4}^{2-}, \mathrm{NO}_{3}^{-}, \mathrm{Br}^{-}, \mathrm{PO}_{4}^{3}$ - $, \mathrm{HCO}_{3}^{-}, \mathrm{C}_{2} \mathrm{O}_{4}^{2-}$, and $\mathrm{BrO}_{3}^{-}$on determination of selenite by variamine blue method was studied by the following
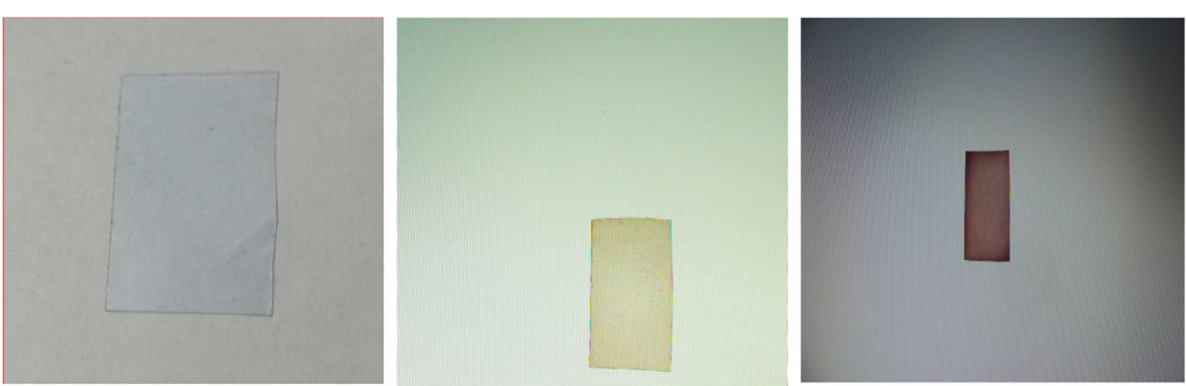

Fig. 2 Change in color of films sorbed with $\Gamma_{3}$ and after treatment with variamine blue dye 

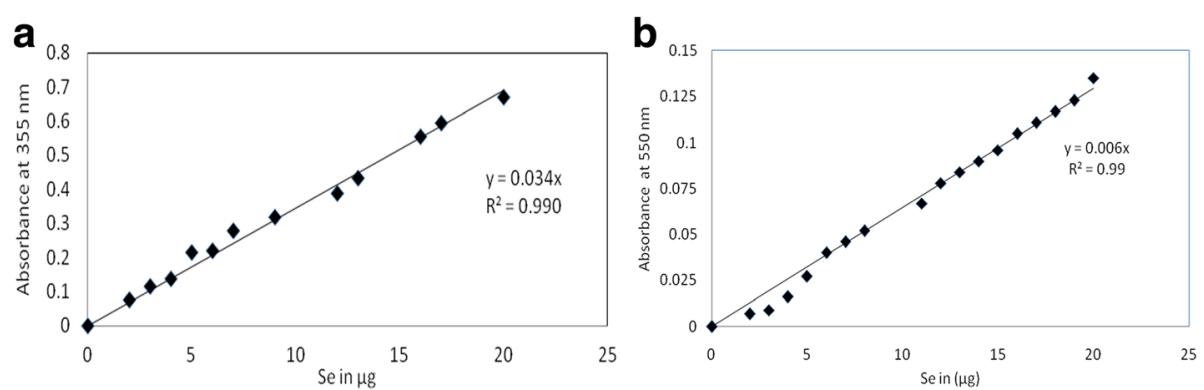

Fig. 3 a Absorbance value of $I_{3}^{-}$loaded films as a function of concentration of $\mathrm{Se}$ (IV) in aqueous solution. $\mathbf{b}$ Calibration curve for variamine blue-oxidized sensor, absorbance recorded at $550 \mathrm{~nm}$. [1 $\mu \mathrm{g} \mathrm{mL} \mathrm{mL}^{-1} \mathrm{Se}(\mathrm{IV}), 1 \mathrm{~mL} 2 \% \mathrm{Kl}$ and $1 \mathrm{~mL} 2 \mathrm{M} \mathrm{HCl}, 3 \mathrm{~mL}$ variamine blue dye solution $\left(8 \times 10^{-5} \mathrm{M}\right)$ and $2 \mathrm{~mL} 1 \mathrm{M}$ sodium acetate with 30 min equilibration]

procedure. The concentration of selenite in the reaction mixture was kept fixed as $7.87 \times 10^{-8} \mathrm{M}$ and the concentration of interfering anion in the equilibrating solution was varied from 0 to 18 times that of the selenite amount and the absorbance was recorded at $550 \mathrm{~nm}$ using protocol described above. The absorbance of variamine blue in the films was plotted as a function of ratio of interfering anions to the moles of selenite $\left[\mathrm{X}^{-}\right] /\left[\mathrm{SeO}_{3}^{2-}\right]$ where $\mathrm{X}^{-}$is the interfering anion. Using this data, the tolerance limits for various anions were determined.

\section{Effect of time on determination of selenite by Variamine blue}

The time required for sorption of $\mathrm{I}_{3}^{-}$into the sensor was studied by recording the absorbance of the $\mathrm{I}_{3}^{-}$sorbed sensor at $355 \mathrm{~nm}$ as a function of time of equilibration at intervals of one minute. The concentration of selenium was fixed at $1 \mu \mathrm{g} \mathrm{mL} \mathrm{m}^{-1}$. The same experiment was repeated for variamine blue oxidized sensor at $550 \mathrm{~nm}$. Plots of absorbance values of the films as a function of equilibration time were obtained.

\section{Application to aqueous samples}

The optimized sensor was used for Se determination in aqueous samples. Tap water samples were spiked with known amount of Se (IV), and the samples were subjected to Se (IV) determination by the present method.
The results of the Se amount obtained were compared with those that were added.

\section{Results and discussion \\ lodometric reaction used}

Equation 1 gives the iodometric reaction between selenite, excess iodide, and acid to liberate molecular iodine. The liberated molecular iodine reacts with excess iodide to form tri-iodide ion.

$$
\begin{aligned}
& \mathrm{SeO}_{3}{ }^{2-}+4 \mathrm{I}^{-}(\text {Excess })+6 \mathrm{H}^{+} \rightarrow \mathrm{Se}+2 \mathrm{I}_{2}+3 \mathrm{H}_{2} \mathrm{O} \\
& \mathrm{I}_{2}+\mathrm{I}^{-} \leftrightarrow \mathrm{I}_{3}^{-}
\end{aligned}
$$

The $I_{3}^{-}$formed during the reaction undergoes in-situ sorption into the sensor. This results into preconcentration of $\Gamma_{3}$ in the films. The films turn yellow after the sorption of tri-iodide. This sorption into the film is stable as the tri-iodide ion in the solution exchanges with chloride ion present in the film as a part of the ion exchanger Al-336. This phenomenon of exchange was proved on the basis that $I_{3}^{-}$sorption did not take place in the films in which Al-336 was not added. The absorption spectra of the films after treatment with variamine blue was again recorded showing an absorption maximum at $550 \mathrm{~nm}$. Figure 1 shows a comparison of the absorption spectrum of blank film, $I_{3}^{-}$loaded film and the film after treatment with variamine blue dye. The blank film is the
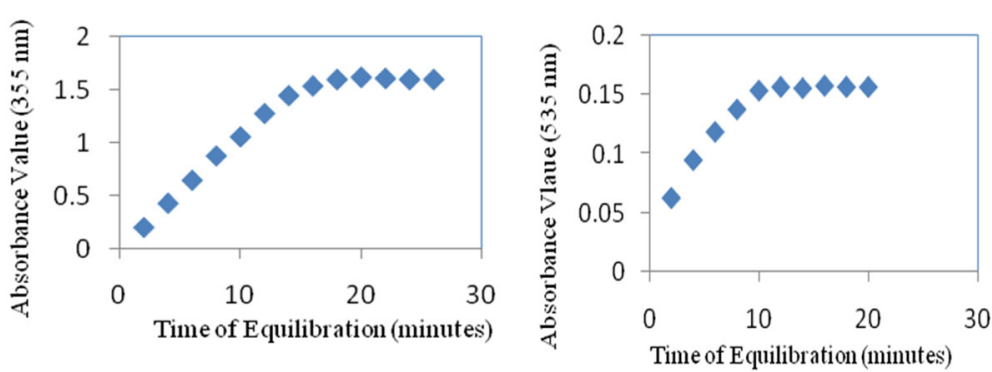

Fig. 4 Variation of absorbance as a function of time of equilibration at 355 and $550 \mathrm{~nm}$ 
film prepared in the present work without treatment with any solution.

The figure depicts a clear change in the absorption spectrum after $\Gamma_{3}$ sorption and treatment with variamine blue dye. Figure 2 shows photographs of the blank film and the film after $I_{3}^{-}$sorption and the film after treatment with variamine blue dye. The films are originally colorless and turn yellow after $I_{3}^{-}$sorption and finally turn violet after treatment with variamine blue dye. The absorbance of the film at the two stages at 355 and $550 \mathrm{~nm}$ was recorded at different concentrations of Se (IV) and a good calibration curve was obtained at both the wavelengths. Figure $3 \mathrm{a}, \mathrm{b}$ shows these calibration plots.

It is observed from Fig. 3a, b that a good linearity is obtained between the absorbance values and concentrations of selenite. The Sandell's sensitivity for $I_{3}^{-}$and variamine blue treatment stage are $2.94 \times 10^{-3}$ and $1.6 \times$ $10^{-2} \mu \mathrm{g} \mathrm{cm}^{-2}$, respectively. The iodometric reaction provides amplification of signal as one mole of Se (IV) gives two moles of iodine. Hence, the reaction provides two fold amplification of the signal.

\section{Time of equilibration}

In order to determine the time required for the ion exchange between $\mathrm{Cl}^{-}$in the film and $I_{3}^{-}$in the equilibrating solution the absorbance of the film was recorded as a function of time of equilibration. It was found that the absorbance value was found to be constant after $20 \mathrm{~min}$ of equilibration. The second stage of equilibration with variamine blue in presence of sodium acetate was found to be completed in about $10 \mathrm{~min}$ of equilibration. Thus, the total time required for measurement was found to be $30 \mathrm{~min}$.

Figure $4 \mathrm{a}, \mathrm{b}$ show the variation of absorbance of the film at 355 and $550 \mathrm{~nm}$ as a function of time of equilibration.

The two plots illustrate that the sorption of $I_{3}^{-}$is comparatively a slower process as compared to the oxidation of variamine blue dye.

\begin{tabular}{lll}
\multicolumn{2}{l}{ Table 1 Effect of interfering anions on Se (IV) analysis } \\
\hline Sr. No & Interfering anion & $\begin{array}{l}\text { Tolerated ratio } \\
{\left[\mathrm{X}^{-}\right] /[\mathrm{Se}(\mathrm{IV})]}\end{array}$ \\
\hline 1 & $\mathrm{PO}_{4}^{3-}$ & 50 \\
2 & $\mathrm{H}_{2} \mathrm{CO}_{3}^{2-}$ & 5 \\
3 & $\mathrm{Cl}^{-}$ & 500 \\
4 & $\mathrm{C}_{2} \mathrm{O}_{4}^{2-}$ & 25 \\
5 & $\mathrm{BrO}_{3}^{-}$ & 5 \\
6 & $\mathrm{NO}_{3}^{-}$ & 100 \\
7 & $\mathrm{Br}^{-}$ & 50 \\
8 & $\mathrm{SO}^{2-}$ & 50 \\
\hline
\end{tabular}

Table 2 Amount of Se (IV) determined by sensor in aqueous samples

\begin{tabular}{lll}
\hline $\begin{array}{l}\text { Amount of Se }(\mathrm{IV}) \text { spiked } \\
\text { to tap water }(\mu \mathrm{g})\end{array}$ & Absorbance & $\begin{array}{l}\text { Amount of Se (IV) } \\
\text { determined by sensor } \\
(\mu \mathrm{g})(n=3)\end{array}$ \\
\hline 3 & 0.05 & $2.42( \pm 0.58)$ \\
9 & 0.197 & $9.38( \pm 0.38)$ \\
12 & 0.273 & $13.00( \pm 0.99)$ \\
15 & 0.330 & $15.71( \pm 0.71)$ \\
18 & 0.399 & $19.00( \pm 0.97)$ \\
\hline
\end{tabular}

\section{Interference studies}

Since iodometric reactions involve an oxyanion, the presence of foreign oxy-anions in solution can affect the determination of Se (IV). Table 1 shows the tolerance limit of the method towards presence of foreign ions in the solution along with selenite.

The table shows that the method can be used without interference in the presence of most of the anions.

\section{Application of the method to determination of selenite in aqueous samples}

The present method when used for determination of $\mathrm{Se}$ (IV) in aqueous samples gave the following results (Table 2).

The results indicate that the amounts of Se (IV) determined by the sensor are in good agreement with the ones that were spiked in the tap water. Thus, the method proves to be useful for determination of Se (IV) in aqueous samples. LOD value for the method is $0.15 \mu \mathrm{g} / \mathrm{mL}$ calculated from the relation $\mathrm{LOD}=3.3(\mathrm{~s} / \mathrm{S})$ where $s$ is the standard deviation of three measurements and $S$ is the slope of the calibration curve. LOQ is $0.52 \mu \mathrm{g} / \mathrm{mL}$, (calculated from the relation $\mathrm{LOQ}=10(\mathrm{~s} /$ S), \% recovery is 99 and \% RSD is 6.94 .

\section{Conclusions}

A simple and rapid method has been developed for determination of Se (IV) in aqueous samples. Polymer inclusion membrane method has been used for the preparation of the sensor. The method is applicable to Selenite determination in the concentration range of 0.2 to $3 \mu \mathrm{g} \mathrm{mL}^{-1}$. The method has been successfully applied to the determination of selenite in aqueous samples. The optical sensor developed in the present work is simple, rapid, cheap, advantageous, and easy to handle. The proposed method can be successfully applied to determination of selenium (IV) in various pharmaceutical and environmental samples.

\section{Authors' contributions}

The orignal idea of the work was planned and executed by PSK. PVR optimized the film preparation and carried out experimental work. SDK helped in interpretation of the results and in the drafting of the manuscript. All authors read and approved the final manuscript. 


\section{Competing interests}

The authors declare that they have no competing interests.

\section{Publisher's Note}

Springer Nature remains neutral with regard to jurisdictional claims in published maps and institutional affiliations.

\section{Author details}

'MES Abasaheb Garware College, Post Graduate and Research Centre, Department of Chemistry, Pune, India. ${ }^{2}$ Modern College Shivajinagar, Department of Chemistry, Pune, India. ${ }^{3}$ S.P. College Pune, Department of Chemistry, Pune, India.

Received: 16 October 2017 Accepted: 4 January 2018

Published online: 13 January 2018

\section{References}

Agrawal K, Patel KS, Shrivas K. Development of surfactant assisted spectrophotometric method for determination of selenium in waste water samples. J Hazard Mater. 2009:161:1245-9.

Alamin MB, Bejey A, Kucera J, Mizera J. Determination of selenium in consumed food items in Libya using instrumental and radiochemical NAA. J Radioanal Nucl Chem. 2006;270:143-6.

Bhagat PR, Pandey AK, Acharya R, Nair AGC, Rajurkar NS, Reddy AVR. Selective preconcentration and determination of iodine species in milk samples using polymer inclusion sorbent. Talanta. 2007;71:1226-32.

Bhagat PR, Pandey AK, Acharya R, Natrajan V, Rajurkar NS, Reddy AVR. Molecular iodine selective membrane for iodate determination in salt samples: chemical amplification and preconcentration. Anal Bioanal Chem. 2008;391: 1081-9.

Bleiman N, Mishael Y. Selenium removal from drinking water by adsorption to chitosan-clay composites and oxides: batch and column tests. J Hazard Mater. 2010;183:590-95.

Capelo JL, Fernandez C, Pedras B, Santos P, Gonzalez P, Vaz C. Trends in selenium determination by AAS or AFS. Talanta. 2006:68:1442-7.

Chen Z, Megharaj M, Naidu R. Speciation of iodate and iodide in seawater by non suppressed ion chromatography with ICPMS. Talanta. 2007;72:1842-6.

Coo L, Cardwell T, Cartroll W, Kolev S. Study of the extraction of 1-(2'-pyridylazo)2-naphthol from ethanol water solutions into nafion membranes. Analytica Clinica. 1999:392:201-11.

Devi P, Jain R, Thakur A, Kumar M, Kumar P. A systematic review and meta -analysis on voltametric and optical techniques for inorganic selenium determination in water. Trends Anal Chem. 2017;95:69-85

Flory P J Principles of polymer chemistry Cornell University press Ithaca 1953.

Hegedus O, Hegedusova A, Simkova S, Pavlik V, Jamova K. Evaluation of the ETAAS and HG-AAS methods of selenium determination in vegetables. J Biochem Biophys Methods. 2008;70:1287-91.

Jagtap $\mathrm{R}$, Maher W. Determination of selenium species in biota with an emphasis on animal tissues by HPLC-ICP-MS. Microchem J. 2016;124:422-529.

Ohki A, Nakagima T, Hirakawa S, Hayashi K, Takanashi H. A simple method of the recovery of selenium from food samples for the determination by ICP-MS. Microchem J. 2016;124:693-8.

Pettine M, McDonald T, Sohn M, Anquandah G, Sharma V. Selenium determination from natural water bodies - a critical review. Trenz Environ Anal Chem. 2015:5:1-7.

Rabiul Awul M, Yaita T, Suzuki S, Shiwaku S. Ultimate selenium(IV) monitoring and removal from water using new class of organic ligand based composite adsorbent. J Hazard Mater. 2015;291:111-9.

Rekha D, Suvardhan K, Kumar KS, Naidu GRK, Chiranjeevi P. Spectrophotometric determination of traces of selenium(IV) in various samples using the flowinjection technique. J Anal Chem. 2006;61:1177-82.

Revansiddappa H, Kiran Kumar T. A facile spectrophotometric method for determination of selenium. Japan Soc Anal Chem. 2001;17:1309-12.

Sears JK, Darby JR. Technology of Plasticizers. Newyork: Wiley; 1982. p. 1174

Ventura M, Stibilj V, do Carmo Freitas M, Pacheco A. Determination of ultratrace elements of selenium in fruits and vegetables samples grown and consumed in Portugal. Food Chem. 2009;115(1):200-6.

Vogel A, Vogel's textbook of quantitative inorganic analysis. III. lodometric Titrations. 1989 384, 10.110.
Yusof A.M, Misni M, Wood A.K.H Determination of inorganic selenium species by NAA in aquatic species after preconcentration using ammonium pyrrolidinecarbodithionate. J Radioanal Nucl Chem 1997 216:59 - 63.

Zhang M, Zhan G, Chen Z. Iodometric amplification method for the determination of micrograms amount of $\mathrm{Mn}(\mathrm{II}), \mathrm{Mn}(\mathrm{VII}), \mathrm{Cr}(\mathrm{III)}, \mathrm{Cr}(\mathrm{VI})$ in aqueous samples. Japan Soc Anal Chem. 1998;14:1077-83.

\section{Submit your manuscript to a SpringerOpen ${ }^{\circ}$ journal and benefit from:}

- Convenient online submission

- Rigorous peer review

- Open access: articles freely available online

- High visibility within the field

Retaining the copyright to your article 